\title{
EVOLUÇÃO URBANA E QUESTÕES SOCIOAMBIENTAIS: UM ESTUDO DE CASO DA OCUPAÇÃO DAS MARGENS DO RIO AMAZONAS NO BAIRRO DE ARAXÁ, MACAPÁ, AMAPÁ BRASIL
}

\author{
URBAN DEVELOPMENT AND ENVIRONMENTAL ISSUES: \\ A CASE STUDY OF THE OCCUPATION TO THE BANKS \\ OF THE AMAZON RIVER IN THE NEIGHBORHOOD OF \\ ARAXÁ, MACAPÁ, AMAPÁ BRAZIL
}

\author{
Jodival Maurício da Costa ${ }^{1}$ \\ Kelvin de Almeida Sacramento ${ }^{2}$ \\ Universidade Federal do Amapá (Unifap), Brazil
}

\begin{abstract}
RESUMO
O presente artigo centra-se em investigar como se configura o espaço urbano do Araxá, na cidade de Macapá, estado do Amapá, Brasil; especificamente na orla do bairro e a relação dos moradores com este ambiente. $\mathrm{O}$ trabalho busca estudar se as atuais propostas de intervenção que envolvem a área de estudo e as famílias que ali residem estão em consonância com o anseio da população local. Para tal, caracterizou-se a área de estudo quanto à infraestrutura urbana, fez-se entrevista com os moradores locais para caracterização dos mesmos no que diz respeito às questões socioeconômicas,

1 Doutor em Ciência Ambiental pela Universidade de São Paulo (USP). Professor do Curso de Arquitetura e Urbanismo da Universidade Federal do Amapá (Unifap), Brasil. Jodival.costa@gmail.com. Membro do Núcleo de Estudos em Estética do Úmido - NEEU/Unifap e do Observatório das Fronteiras do Platô das Guianas - Obfron-Unifap.

2 Arquiteto e Urbanista pela Universidade Federal do Amapá, Brasil. almeida.kelvin@hotmail.com. Membro do Núcleo de Estudos em Estética do Úmido.
\end{abstract}

Fecha de recepción: 09 de octubre del 2015

Fecha de aceptación: 18 de noviembre del 2015 
Jodival Maurício da Costa, Kelvin de Almeida Sacramento. Urban development and environmental issues: a case study of the occupation to the banks of the Amazon river in the neighborhood of Araxá, Macapá, Amapá Brazil.

além de perceber a relação dos habitantes da área com o local e se há satisfação com a atual proposta de intervenção pensada pelo Estado. Precedente à caracterização da área, estudou-se o processo de urbanização das cidades e as principais transformações no espaço amapaense, a fim de compreender o surgimento de espaços desiguais, oriundos do crescimento urbano das cidades, através de revisão bibliográfica. Concluiu-se que as atuais propostas estão dissociadas e alheias ao anseio dos envolvidos nas áreas de intervenção.

Palavras-chave: urbanização; planejamento urbano; estudo de caso; bairro Araxá.

\begin{abstract}
This article focuses on investigating how the urban space of Araxá is configured -specifically on the border of the neighborhood and the residents' relationship with this environment. The job aims at studying if the current proposals for intervention involving the study area and the families who reside there are in line with the desire of the local population. For this purpose, the study area was identified in regards to urban infrastructure; interviews were made to local residents to identify the socio-economic issues, as well as to understand the relationship of the inhabitants of the area with the location, and to know if they are satisfied with the current proposal of intervention intended by the State. Before identifying the area, the urbanization process of towns and major transformations in space Amapá were analyzed in order to understand the emergence of unequal spaces, from the urban development of the cities, through bibliographical revision. It was concluded that the current proposals are disjoined and far from the expectations of those involved in the areas of intervention.
\end{abstract}

Keywords: Urbanization; urban planning; study case; neighborhood Araxá.

\title{
Introdução
}

O processo migratório para os centros urbanos, que no Brasil ocorreu, principalmente, como consequência da busca por melhores condições de vida, acesso aos serviços públicos e oportunidade de emprego, resultou no crescimento demográfico não politicamente planejado dos centros das cidades, além de ter gerado o aumento da malha urbana sem os estudos e ordenamento necessários. Este aumento populacional não foi acompanhado de um planejamento democrático voltado para um ordenamento simétrico do espaço, o que incidiu no agravamento de mazelas sociais e contínua degradação do meio ambiente.

No Brasil este processo se fez presente na maioria das cidades, resultando os problemas acima citados, constantemente visualizados no aumento da pobreza urbana, das habitações insalubres em bairros sem quaisquer serviços de saneamento e nas ocupações irregulares do solo. Desta forma, estes problemas trazem para este trabalho uma discussão que não diz respeito somente ao cenário urbano das cidades, mas a uma análise de como as ações dos agentes que produzem o espaço urbano são determinantes para consolidação da atual situação urbana brasileira. 
Junto às questões urbanas e sociais, uma problemática recorrente nas cidades brasileiras nas últimas décadas diz respeito à degradação ambiental, enfrentada em razão do vertiginoso surgimento das ocupações ilegais, também fruto da produção do espaço desigual. Este cenário de urbanização e degradação ambiental fez-se marcante na Amazônia. Ainda que tal problemática não seja exclusiva da região, a estreita relação com o meio ambiente regional tornou tal questão bastante expressiva nesta escala.

A cidade de Macapá, no Amapá, extremo norte do Brasil, caracteriza-se por esta conjuntura de crescimento urbano sem um planejamento adequado, o que resultou na ocupação de áreas sem infraestrutura planejada para receber habitações. Desta forma, estas áreas são um dos principais problemas urbano, social e ambiental, caracterizados pela precariedade habitacional.

Figura 1: Localização da área de estudo, escala nacional, regional e local

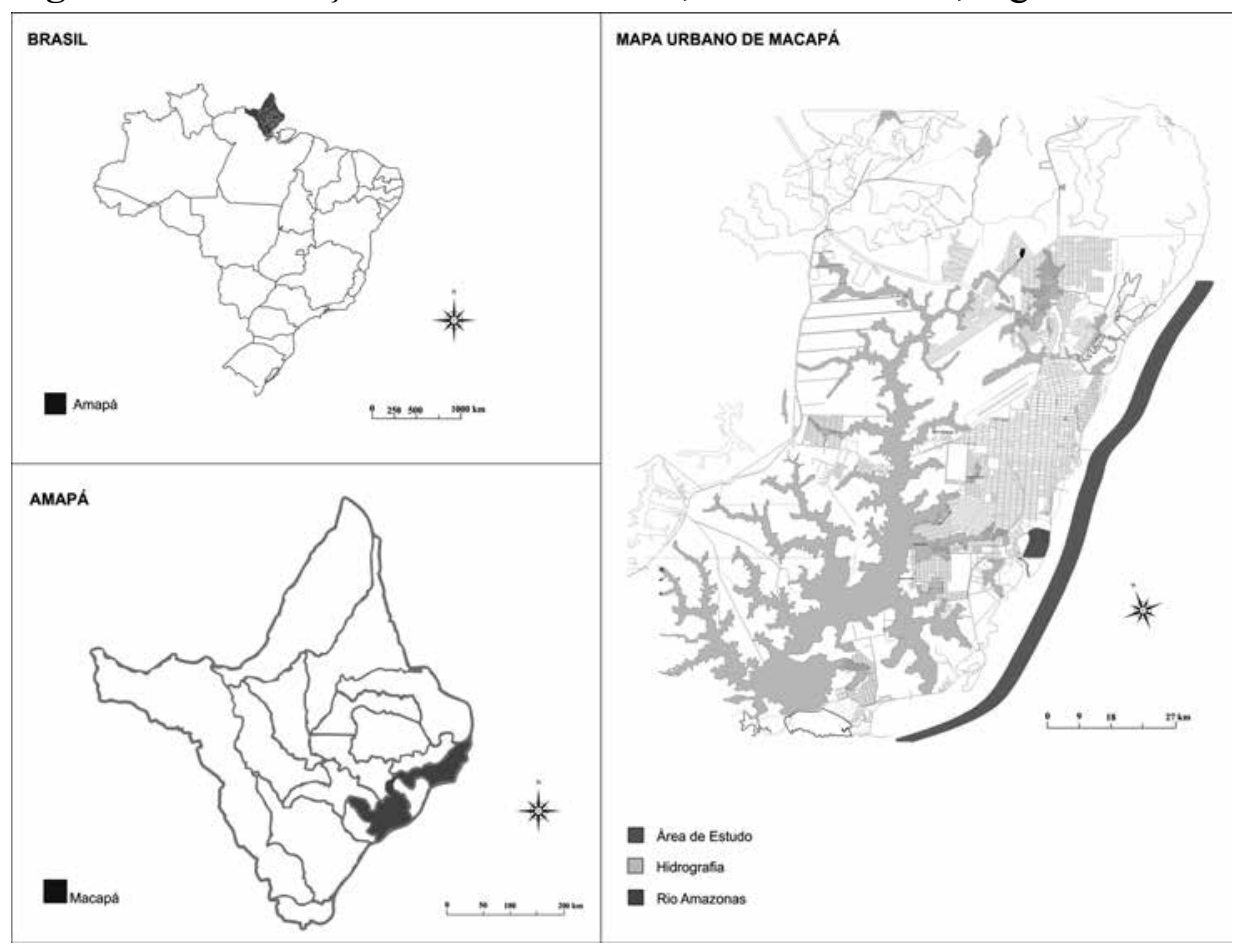

Fonte: Elaborado pelos autores, 2014. 
Dentre os espaços acima mencionados está o bairro Araxá situado na zona sudeste da cidade, e caracterizado pela ocupação das margens do Amazonas, em uma área que até meados da década de 1990 foi intensamente utilizada para fins de lazer, na praia do Aturiá. Neste período o cenário de bares e restaurantes era característico do lugar, mas aos poucos a área foi deixando de ser utilizada pelos habitantes da cidade e o número de habitações aumentou progressivamente, transformando a antiga paisagem de praia, bares e restaurantes.

Contudo os problemas advindos da ocupação não planejada em um local sem infraestrutura foram evidenciados quando a água do rio Amazonas começou a danificar a estrutura das habitações. Em razão das fortes marés e das casas serem construídas em madeira, tornou-se comum famílias serem obrigadas a se retirar do local em razão do risco de desabamento.

Uma grande quantidade de habitações já foi derrubada e as famílias hoje vivem em casa de parentes ou recebem auxílio do Estado para alugarem um apartamento. Atualmente duas obras estão em andamento como proposta de solução para o problema: a construção do muro de arrimo na orla do bairro e um conjunto habitacional, implicando na retirada das famílias do local. Neste sentido, este trabalho centra-se na seguinte questão: as intervenções urbanas pensadas para o bairro estão em consonância com os interesses das famílias que vivem naquele local?

Neste sentido, a pesquisa centra-se em investigar como se configura o espaço urbano do Araxá, especificamente na orla do bairro e a relação dos moradores com este ambiente. Configura-se um estudo de caso da ocupação das margens do Rio Amazonas na cidade de Macapá. Segundo Araújo et al. (2008, p. 4) o estudo de caso consiste numa abordagem metodológica na qual procuramos compreender, explorar ou descrever acontecimentos e contextos complexos, nos quais estão simultaneamente envolvidos diversos fatores. Assim sendo, foram definidas duas técnicas de investigação para a realização deste estudo: a revisão bibliográfica e a pesquisa de campo com aplicação de questionários.

A revisão bibliográfica é aquela em que "os dados secundários são obtidos mediante consulta feita nos livros, revista, jornais, enciclopédias, etc." (Marques 2010, p. 55). Nesse aspecto, foram buscadas fontes secundárias que versam sobre urbanização (em contexto nacional, regional e local), degradação ambiental, planejamento urbano, e as mudanças no 
espaço urbano macapaense a fim de entender a atual conjuntura da cidade e da área a ser estudada a partir de sua evolução urbana.

A pesquisa de campo é na visão de Marques (2010, p. 54) a que "coleta dados primários, ou seja, aqueles obtidos diretamente na fonte, independente se a abordagem é qualitativa ou quantitativa.". Assim, foram aplicados questionários com os moradores da área de estudo para a coleta de fontes primárias, bem como a definição do perfil da população que vive no bairro. Neste formulário foram elencadas as seguintes variáveis: perfil social, características da habitação e infraestrutura urbana, avaliação do meio ambiente e equipamentos sociais e urbanos; e a percepção da relação dos moradores com o rio.

\section{Evolução urbana e degradação ambiental}

O processo de urbanização no Brasil se intensificou a partir da segunda metade do século XX. Segundo Maricato (2001, p. 16) o Brasil aumentou de $26,3 \%$, em 1940 , para mais de $80 \%$, no ano 2000 , o percentual de pessoas vivendo em áreas urbanas. Atualmente, de acordo com o IBGE (Instituto Brasileiro de Geografia e Estatística), a população urbana do país é de $84 \%^{3}$. Tal aumento pode ser justificado pela concentração de atividades econômicas e de serviços públicos que as cidades detêm.

$\mathrm{O}$ rápido crescimento populacional, a falta de ações políticas democráticas para tratar com essa questão e a infraestrutura insuficiente nos centros urbanos fez das cidades um espaço caracterizado por problemas sociais, econômicos e ambientais graves. Mota (2005, p. 815$)$ elenca as principais consequências advindas desta forma de produzir espaço urbano, sendo elas: (i) a falta de condições sanitárias mínimas em muitas áreas; (ii) ausência de serviços indispensáveis à vida das pessoas em muitas partes das cidades; (iii) ocupação de áreas inadequadas; (iv) destruição de recursos de valor ecológico; (v) poluição do meio ambiente; e (vi) habitações em condições precárias de vida. Entendemos que esta se caracteriza como uma forma de produzir o espaço urbano porque se repete nas cidades brasileiras, tornando-se um padrão de governança política: a ação política que favorece os grandes atores produtores do espaço urbano. Nesse aspecto,

3 Entendemos que o conceito de urbanização não se limita ao aumento do número de habitantes das cidades, que este é apenas u dos critérios. Mas neste artigo, o aumento da população nas cidades é o que se torna significativo para a análise dos problemas vivenciados no Aturiá. 
o próprio planejamento urbano se torna um instrumento para garantir os interesses de grupos empresariais que transformam a cidade em espaço de mercadoria e de conflito.

O problema da moradia foi um dos problemas mais agravados no Brasil do Século XX e adentrou o século XXI ainda sem perspectiva de solução. Segundo Maricato (2001), os baixos salários oferecidos pela indústria contribuíram em larga escala para a criação de ambientes com moradias ilegais, haja vista que as famílias não tinham condições de incluírem em seus baixos orçamentos a aquisição de moradias legais. O problema foi atenuado pelo direcionamento da política de Estado para as grandes empresas imobiliárias, "deixando as cidades brasileiras conformarem suas enormes periferias sob o signo da informalidade urbanística e da autoconstrução como única solução habitacional (Ferreira e Uemura 2009, p. 14),"

A consolidação das moradias nas periferias das médias e pequenas cidades ocorre, dentre outros fatores, também pela política de supervalorização das terras nos centros urbanos, que favorece os grandes grupos econômicos atuantes no espaço e urbano e direciona a população da classe baixa e classe média baixa a procurar locais afastados do setor de serviços públicos e privados, embora muitas vezes não distante do centro (Afonso, 2006). Este quadro transformou a urbanização brasileira em "uma máquina de produzir favelas e agredir o meio ambiente" (Maricato, 2008. p. 48). Isto porque muitas favelas estão localizadas em áreas ambientalmente frágeis, tais como: margens de córregos, áreas de mangue, encostas íngremes, áreas de alagamentos e, inclusive, de proteção ambiental, dentre outras. É relevante atentar para uma discussão acerca de uma problemática recorrente nas cidades brasileiras nas últimas décadas, e que se configura com um problema de planejamento urbano: a degradação ambiental, enfrentada em razão do vertiginoso surgimento das ocupações ilegais e das habitações irregulares.

As cidades ao serem intensamente ocupadas atraíram para seus centros não somente o crescimento populacional, mas congregaram problemas sociais, econômicos e urbanos que influenciaram no surgimento ou adensamento da problemática ambiental, que tem se agravado e por isso amplamente discutido no planejamento das cidades. Contudo, as discussões acerca de meio ambiente e meio urbano têm sido tratadas de maneira separada, não atentando para o fato de que os problemas que envolvem 
meio ambiente e cidade estão inseridos numa mesma questão, a produção social do espaço. Segundo Penna (2003) esses problemas são:

produto histórico, espacial e socialmente diferenciado, definido por relações sociais e práticas espaciais que implicam diretamente nas formas de como o território é produzido e consumido, como fenômenos associados num mesmo processo, que corresponde a etapas históricas da produção do espaço (Penna, 2003, p. 3).

Esta construção espacial desigual produz formas urbanas também assimétricas, e isso ocorre, dentre outros fatores, porque o ambiente construído busca atender interesses de agentes político-econômicos historicamente privilegiados para agir na transformação da natureza e no controle sobre a ação das pessoas. O que pesa, nesse sentido, é a produção econômica do e no espaço.

As tramas de interesses condizentes ao processo de produção da cidade passaram a refletir na urbanização, sendo cada vez maior o surgimento de áreas comumente designadas de favelas, onde a pobreza e a falta de serviços públicos eram marcantes. Para Davis (2006 p. 33), as favelas são caracterizadas "pelo excesso de população, habitações pobres ou informais, acesso inadequado de água potável, condições sanitárias e insegurança da posse da moradia". Para o autor as favelas são locais propícios para o surgimento de doenças e favorecem o aparecimento de problemas sociais advindos do processo de segregação social.

Foi a partir da década de 1990 que, segundo Ferreira e Uemura (2009), a escassez de terras para onde a parcela da população mais pobre estava recorrendo ficou dramática. De acordo com os autores, restou para esta população:

Instalarem-se - não sem o apoio muitas vezes irresponsável dos próprios políticos - nas únicas áreas onde, por lei, nem o Estado nem o mercado imobiliário podem atuar: as áreas de proteção ambiental, beiras de córregos, mananciais, encostas de florestas protegidas foram pouco a pouco sendo ocupadas, sob a benevolência do Estado e de toda a sociedade. (Ferreira; Uemura 2011, p.16). 
As questões de meio ambiente constituem grandes problemas para as cidades atuais, principalmente porque vivemos a denominada crise ambiental, que torna mais visível os problemas urbanos como problemas ambientais. Nesse contexto, ganham destaque as áreas urbanas ambientalmente protegidas (AUAP), que em virtude da constituição de tais leis de proteção ambiental, foram transformadas em espaços da ilegalidade, altamente consolidadas e que envolve complexas soluções.

Contudo o agravamento destas questões decorre da falta de assistência pública, uma vez que o Estado não desenvolve ações que possibilitem o usufruto do solo urbano pela população desprovida de moradia, o que contribui significativamente para a ocupação de áreas protegidas. Posteriormente à ocupação, a única solução apontada pelo poder público municipal é a retirada dos habitantes dessas áreas, o que nem sempre é possível, seja pelo nível de consolidação da ocupação, ou pela falta de áreas disponíveis para realocação.

Os moradores de áreas socialmente excluídas, tendo estes como únicos espaços para viver procuram meios de acessar serviços básicos e tentam, por conta própria, melhorar as condições destes lugares, onde acabam transformando e algumas vezes agredindo ainda mais o ambiente natural. Nesse sentido, o próprio processo da degradação não pode ser visto exclusivamente como uma decisão de agredir o ambiente em que se vive, como o resultado da não política habitacional urbana, que emperra a pobreza para as áreas periféricas das cidades.

\section{Questões socioambientais e habitação - a ocupação do Aturiá}

O surgimento do bairro Araxá, situado na zona sudeste da cidade de Macapá (Figura 2) foi consequência da expansão urbana ocorrida em Macapá após a transformação do Amapá em Território Federal. Segundo Santos (2010, p. 56), nos primórdios da década de 80 inicia-se a execução de projetos urbanísticos objetivando o saneamento e a melhoria estética na frontal sul a Fortaleza de São José de Macapá. Dentre esses bairros encontrava-se o Araxá, que segundo o mesmo autor, eram "espaços desordenados, insalubre e seus habitantes eram na maioria ribeirinhos, que sobreviviam do comércio de pescado e da caça". 
DOI: http://dx.doi.org/10.15359/rgac.1-56.12

Jodival Maurício da Costa, Kelvin de Almeida Sacramento. Evolução urbana e questões socioambientais: um estudo de caso da ocupação das margens do rio Amazonas no bairro de Araxá, Macapá, Amapá Brasil.

Figura 2: Mapa urbano de Macapá, localização da área de estudo

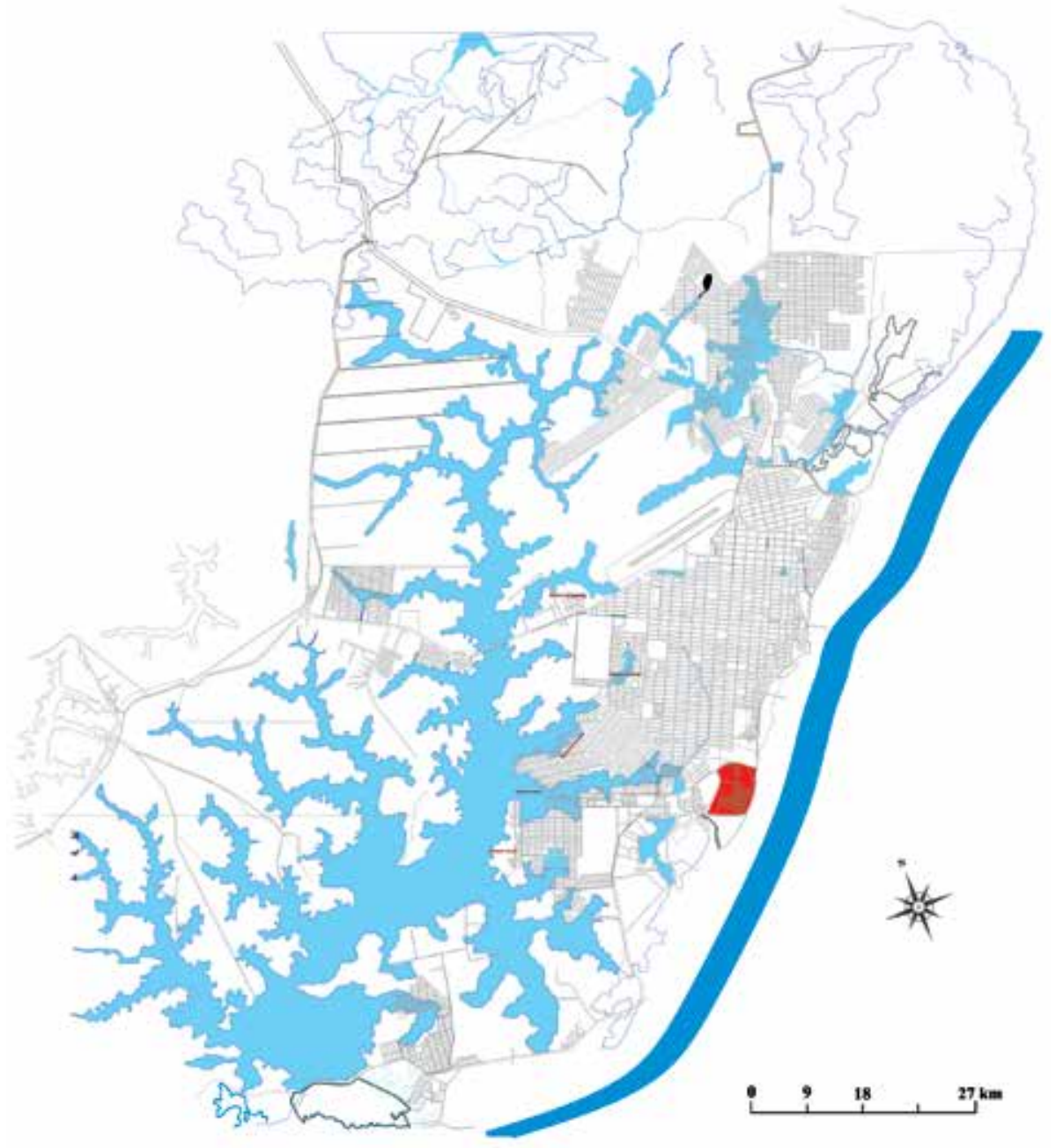

\section{Área de Estudo}

\section{Hidrografia}

Rio Amazonas

Fonte: Elaborado pelos autores, 2014. 
Na década de 1990, esta área foi constantemente utilizada como lazer onde as pessoas frequentavam para se banhar. Por este motivo, por muito tempo o local foi chamado de 'praia do Aturiá'. Naquela década o espaço não era dotado de quaisquer infraestruturas, somente pequenos bares, sendo assim utilizado para fins de lazer. De acordo com os moradores mais antigos ${ }^{4}$, foi em meados da década de 1990 que o Aturiá foi aos poucos deixando de ser frequentado para esta finalidade e as edificações de uso habitacional passaram então a fazer parte do cenário da orla fluvial urbana, causado, sobretudo pela expansão e adensamento do bairro Araxá.

Ocupando inicialmente as margens do rio Amazonas, os moradores adensaram bastante a faixa de orla do bairro e a consequente expansão da malha urbana chegou às pequenas áreas alagadiças, que se tornaram também alvo de acesso e construção de moradias. Hoje essas áreas, margem do rio e área de ressaca constituem-se como um dos principais problemas sociais, econômicos e ambientais do bairro, uma vez que ambas foram ocupadas sem o auxílio de políticas públicas adequadas, causando tais problemas.

As famílias que vivem na orla do bairro Araxá, hoje tem de lidar com o fenômeno da maré que tem avançado e assoreado as margens do rio, obrigando muitas famílias a se retirarem do local. De acordo com a Defesa Civil do Estado-AP, os problemas começaram a se manifestar no ano de 2008, quando um trapiche ruiu em razão da força da maré. Esta obra estava sendo construída para fins de lazer nas programações do Macapá Verão, como forma de incentivar a população a utilizar a área como utilizado na década de 1990, como praia. Desde então, os problemas na orla do bairro vêm se manifestando com maior intensidade. Nos últimos anos tem aumentado cada vez mais o número de residências e passarelas de madeira acometidas pela força da maré e dos fortes ventos dessa área, como pode ser visualizado na Figura abaixo.

4 Informação extraída dos moradores em trabalho de campo, realizado em 2014. 
Figura 3: Casas as margens do Amazonas

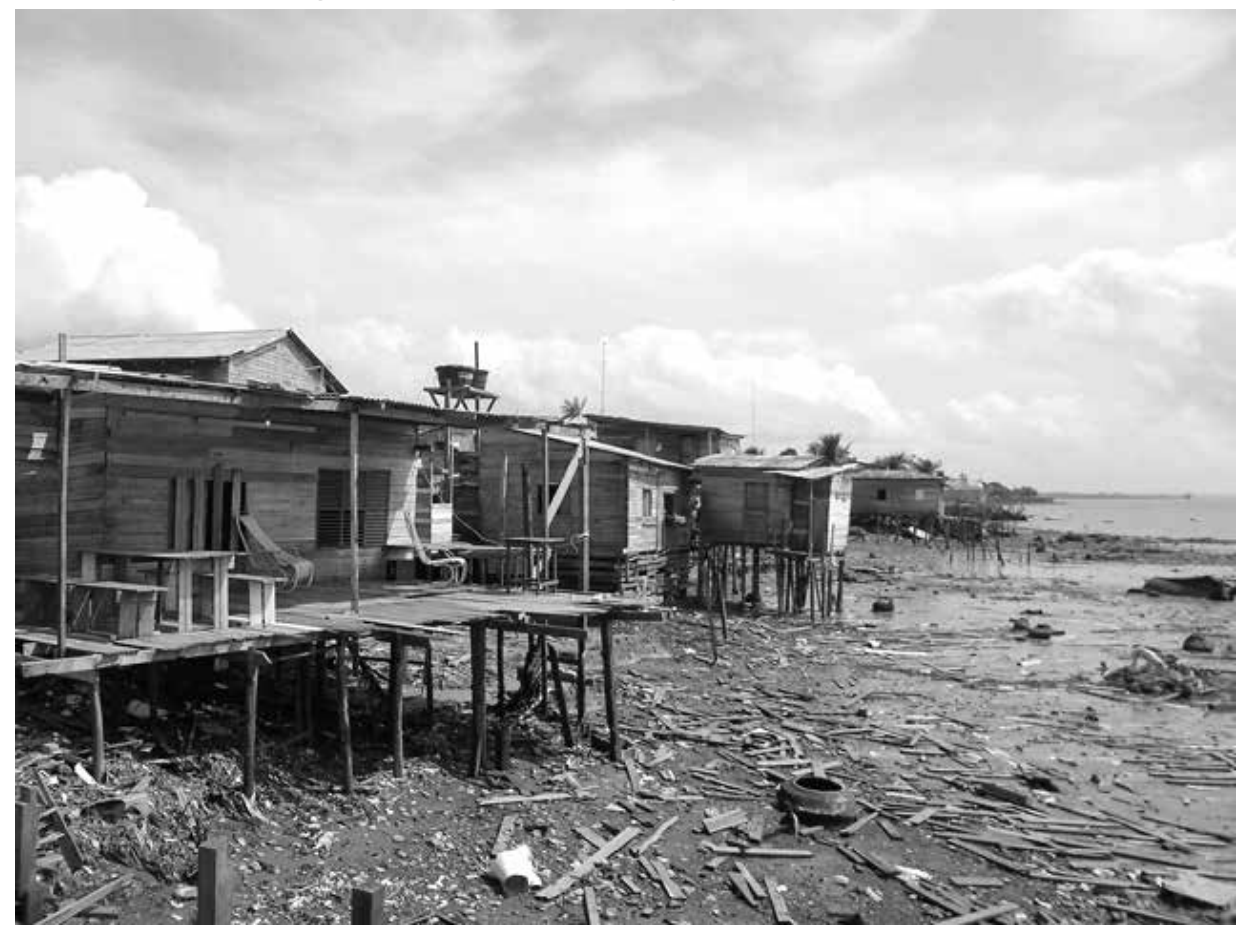

Fonte: Os autores, 2014.

Não obstante, não podemos classificar este problema como natural. De fato, a atual situação de risco na orla do Aturiá foi socialmente construído. Podemos dizer que ele é o resultado da não política pública para a habitação e para o planejamento da cidade.

Atualmente, uma obra para construção de um muro de arrimo vem sendo executada com objetivo de mudar a atual estética do bairro e retirar as famílias do local onde hoje residem. Contudo, os processos burocráticos, as constantes paralizações, só tardam a solução dos problemas enfrentados pelos moradores. No que diz respeito à moradia, há dois anos iniciou-se a construção de 512 (quinhentas e doze) unidades habitacionais a fim de serem entregues às famílias que ainda residem na orla do Amazonas e as que já foram obrigadas a se retirar e hoje vivem em casa de familiares ou recebem auxílio do poder público para aluguel de apartamentos. 


\section{Jodival Maurício da Costa, Kelvin de Almeida Sacramento. Urban development and} environmental issues: a case study of the occupation to the banks of the Amazon river in the neighborhood of Araxá, Macapá, Amapá Brazil.

Há proposta apresentada pelo governo do estado do Amapá é o remanejamento das famílias para o bairro Pedrinhas. Contudo, alguns moradores ainda se recusam a sair do local com a justificativa de não quererem morar em outro bairro ou alegando que o auxílio ofertado pelo poder público é insuficiente para encontrar moradia adequada ${ }^{5}$. As famílias que se recusam a sair são obrigadas a assinarem um termo de compromisso assumindo o risco de ali permanecerem.

Os moradores que vivem nas áreas de ressaca também habitam casas de madeira, usam passarelas de madeira para se locomoverem (Figura 4), sendo estas, em sua maioria deteriorada, dificultando o deslocamento da população residente no local, em especial de pessoas com maiores dificuldades de locomoção, a exemplo de idosos e deficientes físicos.

Figura 4: Casas de famílias que se mantem no local

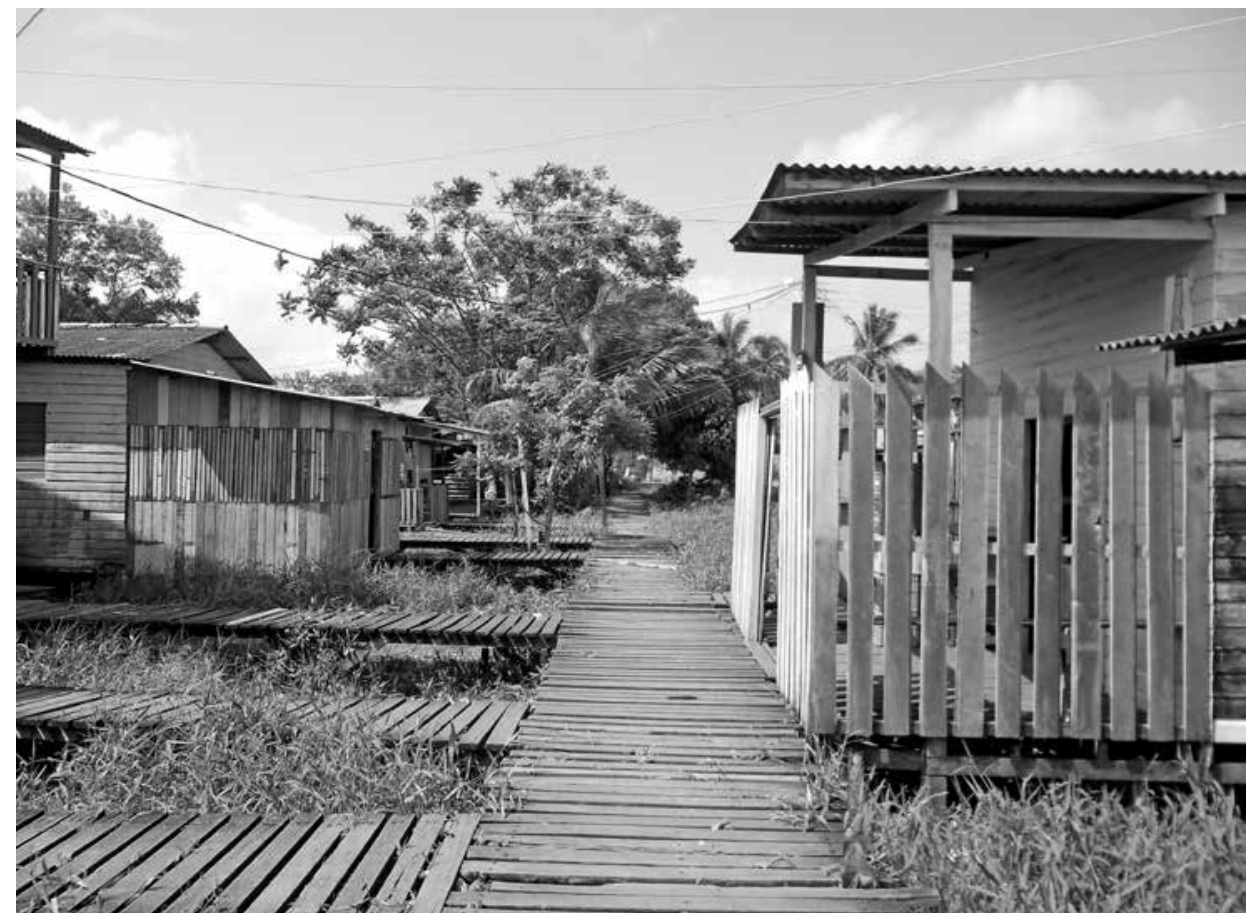

Fonte: Os autores, 2014.

5 De acordo com a Secretária de Inclusão e Mobilização Social o valor do auxílio moradia atualmente é de $\mathrm{R} \$ 350$. 
Outro problema que agrava a situação dos moradores é a insegurança sanitária, pois os serviços de saneamento básico são precários, este na verdade um problema existente em toda a cidade, visto que somente 3\% das residências tem acesso à coleta de esgoto, o restante das casas trata 0 esgoto implantando fossas sanitárias. Realidade comprovada na pesquisa de campo onde $77 \%$ dos entrevistados afirmaram utilizar fossa séptica para despejo dos dejetos. A pesquisa constatou ainda um dado preocupante: $7 \%$ dos moradores despejam em valas a céu aberto e $15 \%$ afirmam despejar em áreas próximas ao rio.

Porem este não é o único problema com relação aos serviços públicos, o abastecimento de água é problemático, de acordo com a Companhia de Água, Esgoto e Saneamento do Amapá (CAESA) mais de 60\% das residências de Macapá não são atendidas por água encanada. Com relação ao bairro do Araxá a maioria das casas possui água encanada, mas de acordo com a Companhia a maior parte foi adquirida de maneira clandestina ${ }^{6}$. Desta forma, com o passar do tempo, iniciou-se o processo de regularização deste sistema, mas ainda é ínfima perto a quantidade de casas que tiveram o acesso de forma irregular.

A iluminação pública é fornecida de maneira precária, através de postes em madeira que muitas vezes ameaçam cair, por conta da falta de manutenção por parte do poder público. Tais postes são constantemente utilizados para obtenção de energia de forma irregular, 64\% dos entrevistados afirmara ter energia elétrica em suas casas, porem a mesma não é fiscalizada pelo órgão fornecedor. ${ }^{7}$

A elevada quantidade de lixo encontrada na área é facilmente visível. Nas áreas alagadiças, em razão do difícil acesso entre as passarelas, o sistema adotado foi a implantação de lixeiras nas entradas das pontes, onde os moradores precisam levar seus lixos até as mesmas para posterior coleta da empresa que presta o serviço. Ainda assim, é possível encontrar lixo em grande quantidade despejado diretamente nas ressacas, comprometendo seriamente a preservação da mesma.

O cenário apresentado denota que a política adotada pelo Estado se configura pela ausência de ações que visem solucionar os problemas

6 Clandestina: aquilo que é contra a lei, irregular, imoral. Dicionário on-line Aurélio. Disponível em: http:// www.dicionariodoaurelio.com/

7 É importante ressaltar que as ressacas, não deveriam receber esses serviços de infraestrutura como água ou luz elétrica, tendo em vista que são áreas de proteção ambiental. 
urbanos, sociais e ambientais enfrentados pelos moradores da área do Araxá. Ou seja, uma política caracterizada pela escolha de não planejar de forma democrática, visto que o Estado detém decisões importantes do que, onde e para quem executar determinadas ações. Tal conjuntura, reflexo da produção do espaço capitalista das cidades que exclui uma grande parcela da sociedade e que é obrigada a viver em comunidades sem serviços básicos e assistência por parte do poder público, onde a própria população, muitas vezes taxada como agressora do meio ambiente, torna-se vítima de uma sociedade desigual que não oferece a todos igual oportunidade de morar bem e acessar aos serviços básicos para uma sobrevivência digna.

\section{Resultados da pesquisa}

Em relação à tipologia da população por local de origem, foi verificado que $63 \%$ da população da área é natural do Estado do Pará, procedente em sua maioria de cidades da região das ilhas paraenses, como Afuá, Breves, Bagre e Anajás. Natural do Amapá representam 29\% e do estado do Maranhã $8 \%$. Este cenário corrobora com estudos anteriores que afirmam que a maioria dos habitantes destas áreas advém das ilhas paraenses.

A respeito da renda, pôde ser constatado que trata-se de uma população de baixo poder aquisitivo: $39 \%$ dos entrevistados vivem com até um salário mínimo, enquanto $46 \%$ tem renda mensal de até dois salários. O percentual de pessoas que vivem com menos de um salário mínimo é de $15 \%$.

$\mathrm{Na}$ pesquisa procurou-se ainda perceber como os moradores notavam a degradação do meio ambiente avaliando a presença de lixo no local onde eles moravam. Percebeu-se então que $69 \%$ considerava alta a quantidade de lixo, enquanto somente $23 \%$ e $8 \%$ consideraram média e baixa, respectivamente.

No que tange os equipamentos sociais, foi avaliado o grau de satisfação dos moradores a respeito de itens como escola, posto de saúde e de segurança. Dentre os graus de satisfação, $65 \%$ dos moradores se mostraram insatisfeitos com os equipamentos sociais e 3\% muito insatisfeitos, este índice elevado foi justificado por muitos moradores pelo fato de não haver no bairro uma unidade básica de saúde. Dentre os entrevistados, 33\% se disseram satisfeitos com os equipamentos sociais, apontado a segurança como um fator que melhorou após a implantação da UPC, além da existência de escolas de ensino infantil no bairro. 
A pesquisa também investigou a relação morador-espaço habitado, se os mesmos gostavam de morar na área, o motivo e atividades relacionadas à utilização do rio. No que diz respeito a morar na antiga praia do Aturiá, 69\% dos entrevistados afirmaram gostar de viver no lugar. Dentre os motivos elencados destacam-se: a proximidade com o centro e o fato de estarem acostumado (percentual de $25 \%$ cada um); o lugar ser calmo $(19 \%)$ e pelo fato de ser próximo do rio $(16 \%)$ e ser uma área bem ventilada $(15 \%)$.

Com relação à utilização do rio para alguma atividade percebeu-se que este elemento natural é a área de lazer da maioria das famílias, 63\% afirmaram utilizar o rio como balneário, $32 \%$ não faz uso do mesmo e 5\% o utilizam para atividades econômicas, geralmente ligadas à pesca.

A maioria dos moradores afirmou que não gostariam de sair da área (95\%), pois se identificam e estão acostumados com o lugar, além de ser próximo ao centro, complementando que apenas gostariam de melhores condições de vida e acesso a serviços de saúde.

No que tange a problemática levantada nesta pesquisa, a investigação demonstrou que a maioria dos moradores não se mostra satisfeito com as atuais propostas de intervenção. Dentre os entrevistados, 95\% não gostariam de sair da área por conta de relação já existente com a mesma após anos morando no local. O que nos permite concluir que as atuais propostas pensadas no contexto urbano macapaense estão dissociadas e alheias ao anseio dos envolvidos nas áreas de intervenção. Mostrando-se assim um planejamento antidemocrático, que abre mão da participação comunitária, em razão das vontades dos agentes que detêm poder de decisão e transformação em larga escala do espaço urbano.

\section{Considerações finais}

As configurações urbanas que caracterizam as cidades são frutos das ações de uma série de agentes responsáveis por práticas sociais determinantes para a construção do espaço urbano. A proliferação das favelas, a urbanização seletiva e degradação de meio natural, são consequências de ações dos que detêm poder de decisão na cidade. Os espaços desiguais onde os menos privilegiados moram em áreas desprovidas de serviços públicos mínimos, apontando para um alto grau de deterioração do meio ambiente e caracterizado por casas que sem condições dignas de habitabilidade, são 
os nítidos exemplos do quão grande é o poder dos agentes que definem tais espaços.

O processo de urbanização e a consequente expansão urbana das cidades brasileiras foram acontecimentos que corroboraram no atual cenário urbano das mesmas, sobretudo se analisado casos específicos, como foi o caso deste trabalho que estudou as mudanças ocorridas no espaço macapaense.

Constata-se que as mudanças ocorridas, inicialmente em 1940 com a implantação de projetos de exploração mineral, e décadas depois com elevação do Território à Estado e a criação da Área de Livre Comércio de Macapá e Santana, contribuíram para o aumento populacional e da malha urbana da cidade, que intensificou o processo de ocupação das margens do rio e das áreas de ressaca.

Ressalta-se ainda que a escolha do Estado em não agir frente ao surgimento dos problemas urbanos e ambientais contribui para a construção de uma cidade caracterizada pela desigualdade, facilmente visualizado no contexto macapaense aqui discutido. A política adotada de não assistir às pessoas que vivem nessas áreas apenas agravou a situação das mesmas e dos locais onde vivem.

No caso das moradias às margens do Rio Amazonas e das áreas de ressaca, a escolha de não planejar e não adotar políticas mitigadoras dos problemas sociais para estas áreas contribuiu na efetivação de um espaço sem infraestrutura urbana, caracterizado pela pobreza, violência e degradação ambiental.

\section{Referencias}

Afonso, C. M. (2006). Sustentabilidade: caminho ou utopia. São Paulo: Annablume.

Araújo, C. Pinto, E. M. F., Lopes, J., Nogueira, L. y Pinto, R. (2008). Estudo de Caso. Métodos de Investigação em Educação. Instituto de Educação e Psicologia, Universidade do Minho, 2008. Disponível em: http://grupo4te.com.sapo.pt/estudo_caso.pdf.

Davis, M. (2006). Planeta Favela. Traduçao Beatriz Medina - São Paulo: Boitempo.

Ferreira, J. S. W. y Uemura, M. (2009). Ações Integradas de Urbanização de Assentamentos Precários Brasília/ São Paulo: Ministério das 
Cidades/Aliança de Cidades. Disponível em: http://www.capacidades.gov.br/media/doc/biblioteca/SNH003.pdf

Maricato, E. (2001). Brasil, cidades: alternativas para crise urbana - Petrópolis.

Maricato, E. (2008). Brasil, cidades: alternativa para a crise urbana. 3. ed. Petrópolis, RJ: Vozes.

Marques, H. R. (2006). Metodologia da pesquisa e do trabalho científico [et al.]. - Campo Grande: UCDB.

Mota, F. S.B. (2005). Conhecimentos para Promoção do Saneamento, Saúde e Ambiente. In: PHILIPPI JR., A. (Ed.). Saneamento, saúde e ambiente. Barueri, SP: Manole. pp 809-832.

Penna, N.A. (2003). A questão urbano ambiental: política urbana e gestão da cidade. Anais do X encontro nacional da Anpur. Disponível em: http://unuhospedagem.com.br/revista/rbeur/index.php/anais/article/ view/2048/2008.

Santos, E. C. (2010). A Modernização do Centro Antigo de Macapá (1943/2005): Políticas Públicas desmemoriadas e superficiais. Dissertação de Mestrado. Universidade Estadual do Ceará. 